\title{
A Serious Game for Patient' Rights Education
}

\author{
Dominique Correia de Oliveira \\ Haute Ecole de Santé Vaud \\ University of Applied Sciences of \\ Western Switzerland) \\ Lausanne, Switzerland \\ ORCID 0000-0003-3419-1469 \\ Yavavli Songuel \\ Haute Ecole de Santé Vaud \\ University of Applied Sciences of \\ Western Switzerland) \\ Lausanne, Switzerland \\ ORCID 0000-0001-7691-0754
}

\author{
Félicia Bielser \\ Haute Ecole de Santé Vaud \\ University of Applied Sciences of \\ Western Switzerland) \\ Lausanne, Switzerland \\ ORCID 0000-0002-4339-9950 \\ Dominique Jaccard \\ Media Engineering Institute \\ University of Applied Sciences of \\ Western Switzerland) \\ Lausanne, Switzerland \\ ORCID 0000-0002-4037-2322
}

\author{
Delphine Bonnard \\ Haute Ecole de Santé Vaud \\ University of Applied Sciences of \\ Western Switzerland) \\ Lausanne, Switzerland \\ ORCID 0000-0003-3941-7615
}

\begin{abstract}
The knowledge and the implementation of patients' rights are fundamental in health professional practices. Courses for healthcare students are often taught using a lecture format. Yet, students find it difficult to understand the importance of legal concepts and apply it to their future practice. In order to promote learner centered teaching practices and encourage knowledge acquisition and practical skills development, the "Patient's Rights \& Innovative Teaching Strategy (PRITS)" project aimed at developing a serious game dedicated to patients' rights education. To design and develop this serious game and the associated learning concept, we set up a multidisciplinary team of experts from the fields of healthcare, law, education and engineering. A collaborative methodology was used to ensure the coherent development of all games and learning elements. The PRITS serious game integrates knowledge about patients' rights into dialogues with virtual patients. It also provides additional resources and exercises related to the topics. The learning experience intends to challenge students' mental models and support a transition from "quality of care only "to "quality of care and respect of patients' rights".
\end{abstract}

Keywords- Patient rights, serious game, serious games design framework, health professional education, higher education, health law

\section{INTRODUCTION}

A maxim says: "Where there is society, there is law". The health sector is also concerned as the law provides a legal framework to the therapeutic relationship between patients and health professionals [1]. When health professionals determine with the patient the appropriate therapeutic management, patients' rights are inseparable from the therapeutic activity because they are the basis of trust in the relationship between the patient and the healthcare provider. However, the application and knowledge of these rights remains complex and sometimes incomplete [2]. The implementation of the appropriate legal rules allows patient centered care (or person-centered care) and thus facilitate therapeutic support in each singular situation.

Therefore, patient's legal rights training is needed in every healthcare education curriculum. However, although most health schools offer courses on this subject, these are mainly ex cathedra lectures with case studies. This approach may not be the most appropriate one to develop the complex needed skills.
Our team developed a serious game, which allows the implementation of active pedagogies and experiential learning. In order to ensure a coherent interaction between the game, content and pedagogical features, we set up a multidisciplinary team including experts from healthcare, law, education and engineering. We used a collaborative framework to guide the design of the serious game and its use in learning situations.

\section{A. Objective}

The Patients' Rights \& Innovative Teaching Strategy (PRITS) project aims at developing a serious game that will support the training of (future) health professionals in the field of patients' rights by encouraging knowledge acquisition and practical skills development.

\section{B. Links With Conference Topics}

This article is linked with the following conference topics: health care, game-based learning, game design and development, healthcare professionals' education.

\section{BACKGROUND}

\section{A. Law and Health}

Legal knowledge is essential for health professionals in order to guarantee the quality of the relationship with the patient [1] and to provide care in accordance with the legal and ethical standards. Some authors, including Burris [3], developed a theory to define and recognize "the law as a social determinant of health".

The quality of health care is at the crossroads between medical and therapeutic services in line with the needs of patients and the respect of the national legal framework. To illustrate this issue, we may consider the example of immunization. If a family with parents, a nine year old son and a sixteen years old teenager come to a clinic to be vaccinated, there are a certain number of questions that emerge from the situation; both clinical questions as well as legal questions that the health care provider needs to address. To whom should what type of information be given? Whose consent should be obtained to vaccinate? The parents? The children? The parents and the children? Is it possible for patients to refuse to be vaccinated? What are the consequences of the refusal? What happens if there are side effects? Is the health professional liable? To be able to respond to these questions, health professionals need to know what legal provisions apply to

(C) 2021 IEEE. Personal use of this material is permitted. Permission from IEEE must be obtained for all other uses, in any current or future media, including reprinting/republishing this material for advertising or promotional purposes, creating new collective works, for resale or redistribution to servers or lists, or reuse of any copyrighted component of this work in other works. 
these cases. The answers will depend on the national law, influenced by international law, doctrine and case law.

In the area of patients' rights, the legislative framework is quite dense. In Switzerland, there is no specific law on patients' rights. Provisions related to patients' rights can be found at international, federal and cantonal levels. In addition, some legislative sources differ between private and public law (e.g. rules applied to data protection). In accordance with the Swiss political structure, there are twenty-six cantonal laws on public health, all of which contain a catalog of patients' rights that is quite similar in some areas while disparate in others.

\section{B. Teaching Law in the Health Sector}

Legal issues are not the primary concern of health professionals [4]. However, students in the health sector should be able to implement legal rights in their future professional context. Therefore, patients' rights are part of law courses in the curricula in health profession education. This subject is taught in different classes at the bachelor and master level, as well as in continuous education courses. Law courses often consist of traditional lectures with case studies. Teaching a subject that is considered less stimulating than the practical topics to be used in clinical practice is a challenge [5]. One of the questions to consider when thinking about the introduction of law courses into a health professional education is "what pedagogical modalities should be used?" It is therefore interesting to consider active pedagogies to engage students in their learning.

\section{Serious Games and Higher Education}

Digitalization leads to new ways of providing healthcare services but also changes teaching and learning. The COVID19 crisis amplified the needs for change in teaching modalities [6]. In education, the current technological transformations could support active pedagogies increasing students' engagement in their learning activities. An example of digitalization in education is the use of serious games for learning purposes. In fact, serious games are recognized to be effective to support new kinds of active pedagogies [7]-[9] and student motivation [10]. A serious gaming approach of patients' rights may thus be considered an appropriate solution to both increase students' motivation and acquisition of declarative knowledge and procedural skills.

\section{Serious Games Development Process}

Designing serious games is a challenging process [8, 11]. The development of relevant serious games implies a systemic and global construction of all games and learning elements. Project teams are usually made up of experts from different disciplines, including teachers, educational engineers, game designers and computer scientists. Collaboration between experts from different disciplines, however, is not straightforward. The collaborative process for the integrated development of the gaming and learning aspects is recognized as key success factors [12 - 14]. It is therefore important to achieve this collaborative process facilitated by a methodological framework.

As illustrated in Fig. 1, this project concerns four domains: (1) healthcare, for the development of clinical scenarios; (2) law, as the field of application that applies to the organization and operation of activities carried out in the interest of patients' health (3), engineering, for the software application development and game technology advice, (4) pedagogy, as the science and art of teaching and learning.

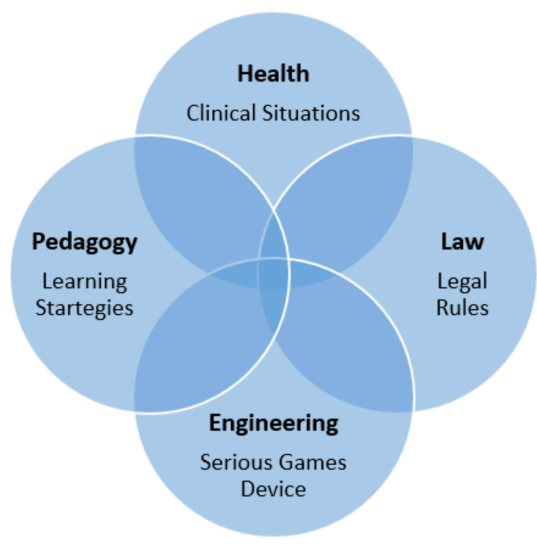

Fig. 1. The four domains involved in the development of the patients' rights serious games

\section{METHODS}

\section{A. Collaborative Multidisciplinary Team}

Serious games development relies on a multidisciplinary team. In the PRITS project, the team was composed of two lawyers, a health professional educator, an educational scientist, two computer scientists, a serious game expert, a graphical designer.

The team followed an iterative and collaborative approach to design and develop the serious game.

\section{B. Design Methodology}

During the design and development process, we tested the co.LAB methodological framework [15]. As presented in Figure 2, this framework brings together all design elements of a serious game into five main categories: (1) Context and objectives; (2) Game design; (3) Learning design; (4) Mechanics; and (5) Assessment. This framework was used all along the project as a guideline and progress-monitoring tool.

We used Nicholson's RECIPE principles [16] for the general design of games and learning incentives.

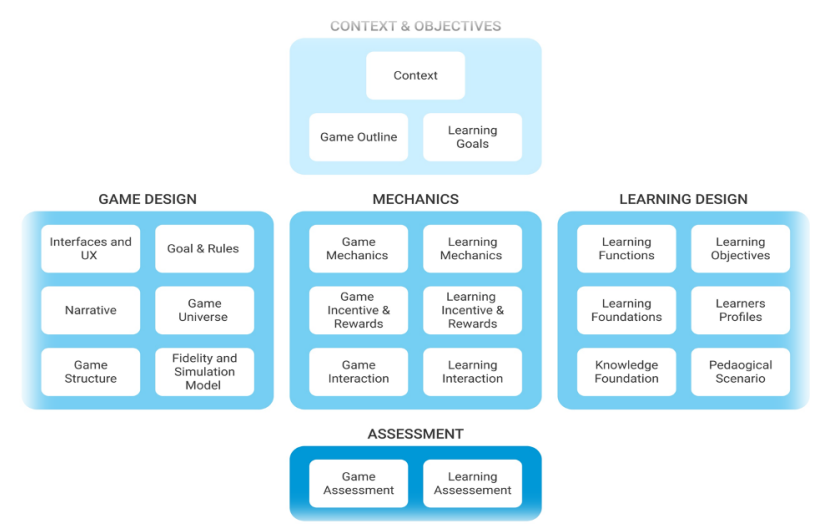

Fig. 2. co.LAB co-design Framework used for the collaborative design of the serious game

\section{Software Development Environment}

For the development of the serious game, we used the open source Wegas authoring system [17]. This authoring system 
has been used for the development of multiple educational serious games $[18$ - 21] and enables collaborative development.

\section{RESUlTS}

\section{A. PRTIS Serious Game Design}

To illustrate the collaborative work and use of the co.LAB framework (figure 2), we present hereafter some of the main design choices for each of the five categories of this framework, respectively: context and objectives, learning design, mechanics, game design and assessment. Even if presented in a linear way in this article, the design process was iterative.

\section{1) Context and Objectives}

The "Context and Objectives" category should enable the project team to have an overview of the problem to be solved and a first idea of the solution.

The learning goals were defined as "providing participants with the knowledge and methods necessary to establish a quality and safe therapeutic relationship, including clinical, environmental and patients' rights elements".

We defined a flexible context of use with possibilities of using the serious game in face-to-face or distant learning with an average number of 150 students per training session.

We also defined a general game outline: "The player takes the role of a carer working in a care environment. His/her objectives are to meet patients' needs while respecting patients' rights. To do this, he/she must be aware of the clinical and legal elements of the situation in order to make the right decisions".

\section{2) Learning Design}

The main objective of the "Learning Design" category is to define and design learning aspects of the serious game and its implementation in a learning context.

We defined specific learning objectives such as "at the end of the serious game, students will be able to know how to search for legal information in order to solve a situation, identify and consult relevant normative documents, establish a decision-making algorithm for the specific situation, explain choices in accordance with the patients' rights".

We identified main learning theories that would support these learning objectives to be achieved. Constructivism was identified as the most purposeful approach for developing a systemic consideration of care. The serious game will be based on a socio-constructivist approach, where the construction of knowledge is integrated into interactions with others, within a social setting. We defined the pedagogical scenario for the integration of the serious game in the curriculum and in particular in the classes on patients' rights. In parallel to the game, briefing and debriefing sessions are planned, based on [22 - 24]. The teacher will get the students to interact and use the notion of socio-cognitive conflict (confrontation between divergent opinions) to allow the reconstruction of a common knowledge. This will be done by confronting students who have made different choices in a similar situation within the serious game.

The development of the educational content in the serious games was carried out in accordance with the clinical and legal experience of the project team members. The scenarios were derived from real-life clinical situations that concern legal issues such as capacity of discernment, accessibility to care or freedom of choice.

\section{3) Mechanics}

Mechanics are at the core of serious games design. They link the learning design to the game design. Games mechanics are the set of actions repeated by the player all along the game [25]. Learning mechanics can include activities such as remembering, understanding, applying, analyzing, evaluating or creating. Learning effectiveness increases when learning and game mechanics are aligned together, and in relationship with learning objectives [16], [26 - 28].

We defined the main game mechanic as "dialogues with virtual patients". This mechanic is aligned with the main learning mechanics which are to apply a theoretical concept to solve a complex situation, to exchange between students on the choice to be made in the simulation, to answer questions posed by virtual health actors (doctors, lawyer).

For game and learning incentives and rewards, we relied on the RECIPE approach to meaningful gamification [16] with the following motivational elements:

- Autonomy (being able to choose between several paths). In dialogues, students have several choices available. Students also have the possibility to choose the order in which the patients should be seen.

- Mastery (learning to the point of mastering a skill). Students should go from simple cases, where they learn first about a rule, to more complex situations where they will apply this rule. This should increase the feeling of mastery.

- $\quad$ Relatedness (not feeling alone, feeling connected to other people). Relatedness will be introduced during training sessions by having students working in teams, discussing to choose the most appropriate answer in the dialogues.

\section{4) Game Design}

The "Game Design" category aims at defining all game elements of the serious game.

Concerning fidelity, we have defined that, depending on the educational objectives, the search for cognitive and emotional fidelity was more important than sensory fidelity (sounds and images) [29].

Thus, for the simulation model, we developed small but strongly coherent dialogues that correspond to possible and meaningful professional situations. The options offered in those dialogues should lead to complex reflections on the trade-off between quality of care and patients' rights.

\section{5) Assessment}

As from the design phase, we defined the assessment process. The learning assessment will include both a performance assessment and a subjective assessment. The performance assessment will be performed through pre-test and post-test questionnaires that are integrated in the game. To assess the learning subjectively, we will use an adapted version of the Serious Games Evaluation Scale (SGES) [30]. The game assessment will be done with the French version of AttrakDiff standard questionnaire [31], [32]. 


\section{B. Serious Game Development}

Computer scientists and designers developed the game while legal experts created and captured the content. We used an iterative approach with frequent coordination meetings between teachers, computer scientists and experts from legal or game aspects.

User interfaces were developed in an iterative way, between graphical designer, game designer and teachers.

Narrative contents were defined and implemented through the Wegas authoring dialogue interfaces.

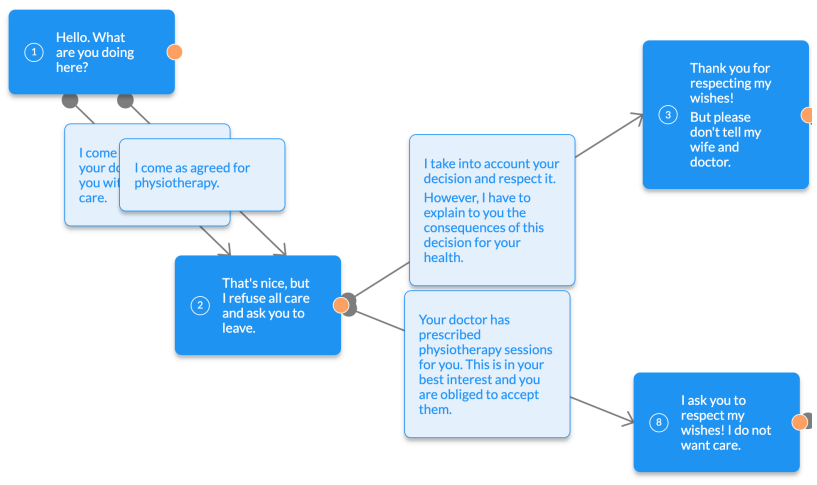

Fig. 3. Narrative contents editor

\section{Prototype of the Patients' Rights Serious Game}

The PRITS serious game has been developed with the following functionalities:

- Simulation of dialogues and decision making in different scenarios related to patients' rights

- Handling multiple patients, dialogues and exercises

- An instructor interface to follow up students progresses

The following screenshots show some examples of the game interface, exercises and dialogue with a patient.

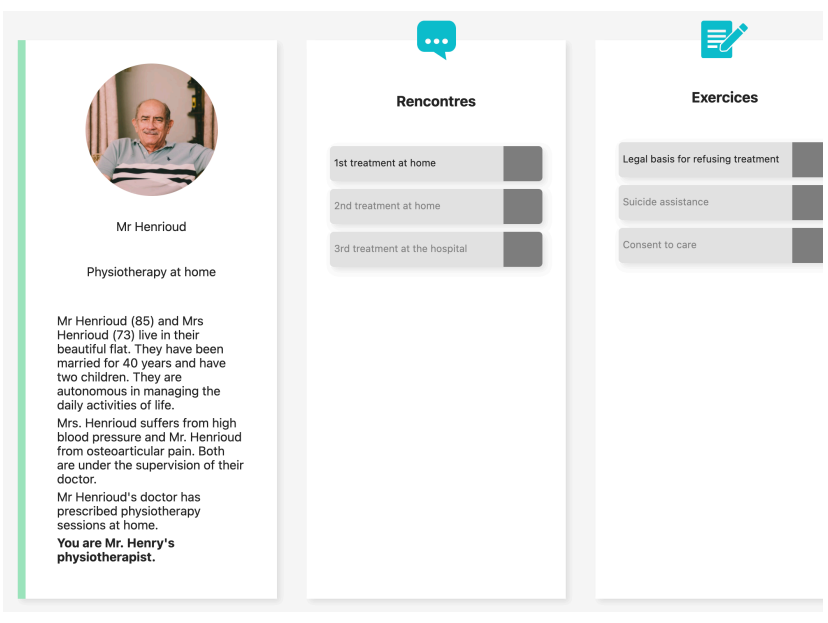

Fig. 4. Example of multiples possible dialogues and corresponding exercises linked to a patient
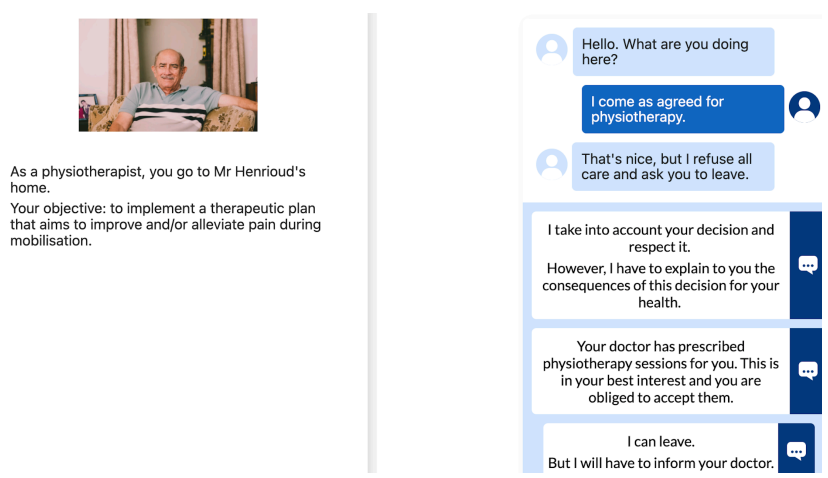

Fig. 5. Screenshot of a dialogue with a patient

\section{DISCUSSION}

\section{A. co.LAB Methodological Framework}

The co.LAB framework allowed for a collaborative design of the serious game elements and ensured a coherence between them. The framework provided a continuous access to an overview of elements related to the usage context, the game and learning aspects and the assessment. This facilitated a shared vision of the "serious game" artefact from experts of different disciplines.

We discovered that this framework was also usable as a project monitoring tool. As presented in the following figure, we used it as a tracking progress tool indicating the progress by filling the elements with green color.

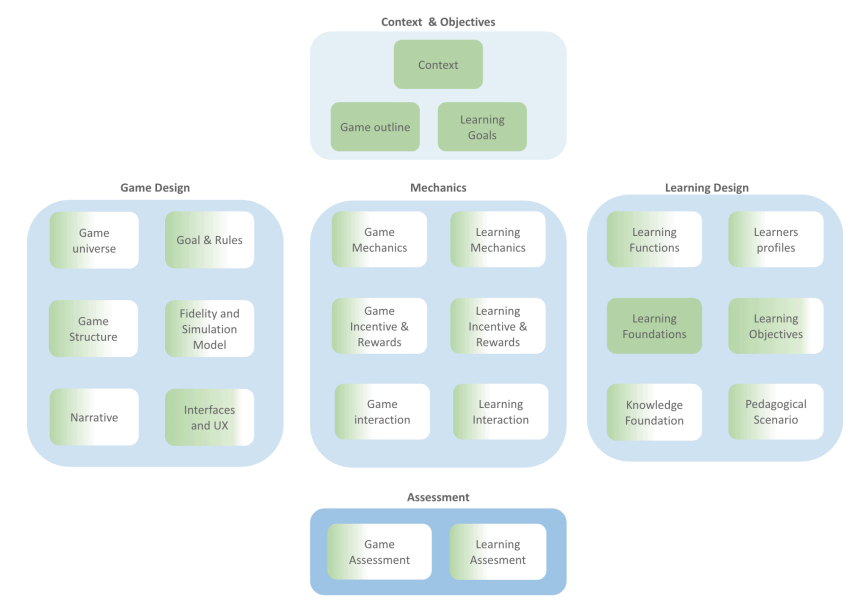

Fig. 6. Use of the co.LAB framework as a project monitoring tool

\section{B. PRITS Serious Game Expectations}

The PRITS serious game is developed and ready to be included in a pedagogical concept, enabling learner centered teaching practices and active pedagogies like problem-based learning, situated learning or experiential learning [8, 27, 33].

In the serious game, students should be encouraged to develop their knowledge through experiences in dialogues with virtual patients. By offering possibilities such as interactive narrations and direct feedback, this serious game allows healthcare students to be immersed in professional situations that are relevant to patients' rights. This immersion is carried out in situations where patients' rights must be mobilized, such as when a health professional informs a patient of the various consequences of a therapeutic decision, 
thus ensuring the patient's "right to information". With those experiences, students should be able to adapt their mental models from "quality of care only» to "quality of care and respect of patients' rights". The transfer between different situations is encouraged through the variety of dialogues with different virtual patients. We believe that by providing meaningful scenarios associated with debriefing sessions, we could facilitate the transfer from simulation to "real" practice.

We believe that both the playful elements and the link between simulated situations and students' future profession may increase students' motivation.

\section{Limitations}

The main limitation is that the game has not yet been implemented and the objectives have not yet been evaluated. Even if most of the screenshots are in English, the serious game is currently only available in French, which is the language of our target audience. If we want to extend this game to other audiences, the game content will have to be translated but also adapted to the legal framework of the targeted regions or countries.

\section{Future Work}

First use of the serious game by health students (approximately 150 Bachelor nursing students) is planned in Autumn 2021. An assessment is planned in September 2021, after the first use in class (see assessment section).

\section{CONCLUSION}

Despite their implication for the quality of care, law courses and patient legal rights are often not the primary concern of health professionals. These topics are part of the healthcare curricula; however, healthcare students often lack motivation for and engagement with these non-practical topics. Active pedagogies supported by new tools as serious games may be a way to support students' learning by providing meaningful situations where knowledge related to patients' rights make sense. The co.LAB framework [15] supporting collaborative and integrated teamwork appears to be a suitable methodology to transform these goals into meaningful features (objectives, mechanics, and so on). Supported by this framework, the developed serious game forms a global and coherent learning tool based on the principles of gaming and education. The Wegas [17] technological infrastructures used to develop the serious game facilitated collaborative work and parallel progression. The expected outcomes are to support patients' rights education and to increase students' motivation at learning this subject. By implementing the serious game in the learning program for healthcare professionals, we will be able to assess these outcomes. These results should open new pedagogical perspectives, as the possibility to broaden the use of the PRITS serious game to continuous education.

\section{VIII.ACKNOWLEDGMENTS}

The digital skills center of the HES-SO (CCN) supports the PRITS project. PGBDS8-104294

The Swiss National Science Foundation (NRP 77) supports the co.LAB project.

\section{REFERENCES}

[1] D. Manaï, "Médecine et droit: pour un pacte humaniste au-delà du conflit," in Droit de la santé et médecine légale, Éditions Médecine et Hygiène., Chêne-Bourg, 2014, pp. 13-19.
[2] S. Iltanen, H. Leino-Kilpi, P. Puukka, and R. Suhonen, "Knowledge about patients' rights among professionals in public health care in Finland," Scandinavian journal of caring sciences, vol. 26, no. 3, pp. 436-448, 2012, doi: 10.1111/j.1471-6712.2011.00945.x.

[3] S. Burris, "Law in a social determinants strategy: a public health law research perspective," Public health reports, vol. 126, no. 3_suppl, pp. 2227, 2011, doi: 10.1177/00333549111260S305.

[4] T. W. Harding, "L'influence du droit sur la relation entre médecins, malades et la société," in Droit de la santé et médecine légale, Éditions Médecine et Hygiène., Chêne-Bourg, 2014, pp. 13-19.

[5] D. T. Bess, J. Taylor, C. A. Schwab, J. Wang, and J. A. Carter, “An innovative approach to pharmacy law education utilizing a Mock Board of Pharmacy Meeting," Innovations in pharmacy, vol. 7, no. 1, 2016, doi: 10.24926/iip.v7i1.419.

[6] R. Remtulla, "The Present and Future Applications of Technology in Adapting Medical Education Amidst the COVID-19 Pandemic," JMIR medical education, vol. 6, no. 2, p. e20190, 2020, doi: 10.2196/20190.

[7] S. V. Gentry et al., "Serious gaming and gamification education in health professions: systematic review," Journal of medical Internet research, vol. 21, no. 3, p. e12994, 2019, doi: 10.2196/12994.

[8] P. Rooney, "A Theoretical Framework for Serious Game Design," International Journal of Game-Based Learning, vol. 2, no. 4, pp. 41-60, 2012, doi: 10.4018/ijgbl.2012100103.

[9] E. A. Boyle et al., "An update to the systematic literature review of empirical evidence of the impacts and outcomes of computer games and serious games," Computers and Education, vol. 94, pp. 178-192, 2016, doi: 10.1016/j.compedu.2015.11.003.

[10] M. Dankbaar, "Serious games and blended learning; effects on performance and motivation in medical education," Perspectives on Medical Education, vol. 6, no. 1, pp. 58-60, 2017, doi: 10.1007/s40037-016-0320-2. [11] O. De Troyer, "Towards effective serious games," in 2017 9th International Conference on Virtual Worlds and Games for Serious Applications (VS-Games), 2017, pp. 284-289, doi: 10.1109/VSGAMES.2017.8056615.

[12] D. Djaouti, "Serious Games pour 1,éducation: utiliser, créer, faire créer ?," Tréma, vol. 4, pp. 51-64, 2016, doi: 10.4000/trema.3386.

[13] Y. Chaudy, T. M. Connolly, and T. Hainey, "EngAGe: A Link between Educational Games Developers and Educators," in 2014 6th International Conference on Games and Virtual Worlds for Serious Applications (VSGAMES), Valletta, Malta, 2014, pp. 1-7, doi: 10.1109/VSGames.2014.7012156.

[14] J. Bourgonjon, F. De Grove, C. De Smet, J. Van Looy, R. Soetaert, and M. Valcke, "Acceptance of game-based learning by secondary school teachers," Computers and Education, vol. 67, pp. 21-35, 2013, doi: 10.1016/j.compedu.2013.02.010.

[15] D. Jaccard, L. Suppan, E. Sancehz, A. Huguenin, and M. Laurent, “A Generic, Adaptive and Systemic Methodology for the Collaborative Design of Serious Games: Development of the co.LAB Framework," JMIR Serious Games Preprints, 2021, doi: 10/03/2021:28674.

[16] S. Nicholson, "A RECIPE for Meaningful Gamification," in Gamification in Education and Business, T. Reiners and L. C. Wood, Eds. Cham: Springer International Publishing, 2015, pp. 1-20.

[17] M. Laurent, C. Junod, J. Hulaas, D. Jaccard, and F.-X. Aeberhard, Wegas authoring system. 2017.

[18] P. Delmas et al., "Effects of environmental distractors on nurse emergency triage accuracy: a pilot study protocol," Pilot and Feasibility Studies, vol. 6, no. 1, p. 171, Nov. 2020, doi: 10.1186/s40814-020-00717-8. [19] J. Hulaas et al., "A serious game for studying decision making by triage nurses under stress," in International Conference on Games and Learning Alliance, 2020, pp. 253-262, doi: doi.org/10.1007/978-3-030-63464-3_24.

[20] R. Bonazzi, S. Missonier, D. Jaccard, P. Bienz, B. Fritscher, and E. Fernandes, "Analysis of Serious Games Implementation for Project Management Courses," Oct. 2011, doi: 10.1007/978-3-7908-2789-7_53.

[21] M. Plumettaz-Sieber, J. Hulaas, E. Sanchez, and D. Jaccard, “Co-design of a serious game for computing education," presented at the Gamification \& Serious Games Symposium (GSGS), Neuchâtel, Switzerland, 2019, Accessed: Mar. 03, 2021. [Online]. Available: https://ludovia.ch/2019/wpcontent/uploads/2019/04/Actes-2019_V4.pdf.

[22] I. Motola, L. A. Devine, H. S. Chung, J. E. Sullivan, and S. B. Issenberg, "Simulation in healthcare education: A best evidence practical guide. AMEE Guide No. 82," Medical Teacher, vol. 35, no. 10, pp. e1511-e1530, Oct. 2013, doi: 10.3109/0142159X.2013.818632. 
[23] J. W. Rudolph, D. B. Raemer, and R. Simon, "Establishing a Safe Container for Learning in Simulation: The Role of the Presimulation Briefing," Simulation in Healthcare: Journal of the Society for Simulation in Healthcare, vol. 9, no. 6, pp. 339-349, Dec. 2014, doi: 10.1097/SIH.0000000000000047.

[24] S. Boet, J.-C. Granry, and G. Savoldelli, La simulation en santé De la théorie à la pratique. Springer, 2013.

[25] K. Salen, K. S. Tekinbaş, and E. Zimmerman, Rules of play: Game design fundamentals. MIT press, 2004.

[26] J. L. Plass, B. D. Homer, C. Kinzer, J. Frye, and K. Perlin, "Learning mechanics and assessment mechanics for games for learning," G4LI White Paper, vol. 1, p. 2011, 2011, doi: 10.13140/2.1.3127.1201.

[27] J. L. Plass, B. D. Homer, and C. K. Kinzer, "Foundations of game-based learning," Educational Psychologist, vol. 50, no. 4, pp. 258-283, 2015.

[28] S. Arnab et al., "Mapping learning and game mechanics for serious games analysis," British Journal of Educational Technology, vol. 46, no. 2 , pp. 391-411, 2015, doi: 10.1111/bjet.12113.

[29] X. Ye, P. Backlund, J. Ding, and H. Ning, "Fidelity in Simulation-based Serious Games," IEEE Transactions on Learning Technologies, vol. PP, no. c, pp. 1-1, 2019, doi: 10.1109/TLT.2019.2913408.
[30] E. Fokides, P. Atsikpasi, P. Kaimara, and I. Deliyannis, "Factors influencing the subjective learning effectiveness of serious games," Journal of Information Technology Education:Research, vol. 18, pp. 437-466, Oct. 2019, doi: 10.28945/4441.

[31] C. Lallemand, V. Koenig, G. Gronier, and R. Martin, "Création et validation d'une version française du questionnaire AttrakDiff pour l'évaluation de l'expérience utilisateur des systèmes interactifs," European Review of Applied Psychology, vol. 65, no. 5, pp. 239-252, 2015, doi: 10.1016/j.erap.2015.08.002.

[32] M. Hassenzahl, M. Burmester, and F. Koller, "AttrakDiff: Ein Fragebogen zur Messung wahrgenommener hedonischer und pragmatischer Qualität," in Mensch \& computer 2003, Springer, 2003, pp. 187-196.

[33] D. A. Kolb, R. E. Boyatzis, and C. Mainemelis, "Experiential learning theory: Previous research and new directions," Perspectives on thinking, learning, and cognitive styles, vol. 1, no. 8, pp. 227-247, 2001. 